\title{
Educação republicana e democrática: potencialidades e desafios para a formação inicial docente
}

Republican and democratic education: potentialities and challenges for initial teacher education

Educación republicana y democrática: potencialidades y desafíos para la formación
inicial del docente

Maria Regina Johann*
Paulo Evaldo Fensterseifer

\section{Resumo}

O artigo trata de aspectos da formação inicial (FI) que visam assegurar princípios republicanos e democráticos evidenciados nas leis e diretrizes da sociedade brasileira. Objetiva-se refletir acerca das noções que os professores da escola básica têm acerca da laicidade e, por consequência, intenciona-se dar visibilidade a esta perspectiva formativa como uma possibilidade de assegurar princípios republicanos e democráticos. Referencia-se em autores que tratam da Escola Republicana (ER); na Constituição nacional de 1988; na Lei de Diretrizes e Bases da Educação Nacional, Lei n 9.394/1996; e nas Diretrizes Curriculares Nacionais para a Educação Básica; com inspiração em uma tarefa desenvolvida no interior da disciplina de Educação Brasileira. Nela, os acadêmicos entrevistam professores de escolas públicas, de diferentes áreas de conhecimento, acerca do entendimento de ER, e as possíveis implicações deste entendimento para as aulas e para o conjunto das atividades desenvolvidas nas escolas em que atuam. A partir deste diálogo, o tema adentra as aulas da referida disciplina e é tematizado à luz dos princípios da ER. Como resultado, constatam-se: o desconhecimento do tema pela grande maioria dos professores, especialmente aqueles com mais tempo de atuação no Magistério e a (quase) ausência do tema em cursos de formação continuada. De nosso horizonte de compreensão, argumentaremos a favor da presença do referido tema nos cursos de Fl, a partir do entendimento de que a especificidade da educação escolar, em sociedades democráticas, necessita pautar-se pelos princípios da ER.

Palavras-chave: Formação de professores. Laicidade. Competência republicana.

Recebido em 30/12/2020 - Aprovado em 05/10/2020

http://dx.doi.org/10.5335/rep.v27i3.12380

Doutora e mestre em Educação nas Ciências pela Universidade Regional do Noroeste do Estado do Rio Grande do Sul (Unijuí). Professora efetiva da Unijuí. Orcid: https://orcid.org/0000-0002-2788-5967. E-mail: maria.johann@unijui.edu.br

** Doutor em Educação pela UNICAMP. Professor do Departamento de Humanidades e Educação da Universidade Regional do Noroeste do Estado do Rio Grande do Sul - Unijuí. Professor do Programa de Pós Graduação em Educação nas Ciências - Mestrado e Doutorado. Orcid: https://orcid.org/0000-0002-4914-5281. E-mail: fenster@unijui.edu.br 


\section{Abstract}

This study thematizes aspects of the initial education (IE) that aim to assure republican and democratic principles evidenced in laws and directives of Brazilian society. It aims to reflect on the notions that basic school teachers have about secularism and, consequently, it is intended to give visibility to this formative perspective as a possibility to ensure republican and democratic principles. It has as its references authors who study the Republican School (RS); in the National Constitution of 1988; in the Law of Guidelines and Bases of National Education, Law no. 9.394/1996; in the National Curriculum Guidelines for Basic Education. It is inspired by a task developed in the discipline of Brazilian Education. In it, academics interview public school teachers from different disciplines about their understanding of RS and their possible implications in their classes and in the activities developed in their schools. From this dialogue, the theme in included in the classes of that discipline and is thematized in the light of the principles of RS. As results, we found: a lack of knowledge of the theme by the majority of teachers, especially those with longer working time, and an (almost) absence of the theme in continuing education courses. From our perception, we argue in favor of the presence of this theme in IE courses, understanding that the specificity of school education in democratic societies needs to be guided by the principles of RE.

Keywords: Teacher education. Secularity. Republican competence.

\section{Resumen}

El artículo aborda aspectos de la formación inicial $(\mathrm{Fl})$ que miran asegurar principios republicanos y democráticos evidenciados en las leyes y directrices de la sociedad brasileña. El objetivo es reflexionar sobre las nociones que los docentes de la escuela básica tienen sobre la laicidad y, en consecuencia, la intención es dar visibilidad a esta perspectiva formativa como una posibilidad para asegurar principios republicanos y democráticos. Se basan en autores que tratan de la Escuela Republicana (ER); en la Constitución Nacional de 1988; en la Ley de Directrices y Bases de la Educación Nacional, Ley no 9.394/1996; en las Directrices Curriculares Nacionales para la Educación Básica. Nos inspiró una tarea desarrollada dentro de la disciplina de Educación Brasileña. En ella, los académicos entrevistan profesores de escuelas públicas, de diferentes áreas del conocimiento, a respecto del entendimiento de ER, y las posibles implicaciones de este entendimiento para las clases y para el conjunto de las actividades desarrolladas en las escuelas en que actúan. A partir de este diálogo, el tema adentra en las clases de la referida disciplina y es tematizado a la luz de los principios da ER. Como resultado encontramos: la falta de conocimiento del tema por la grande mayoría de los maestros, especialmente aquellos con más tiempo de actuación en la enseñanza y a (casi) ausencia del tema en los cursos de educación continuada. De nuestro horizonte de comprensión argumentaremos en favor de la presencia del referido tema en los cursos de FI desde el entendimiento de que la especificidad de la educación escolar, en sociedades democráticas, debe guiarse por los principios da ER.

Palabras clave: Formación de profesores. Secularidad. Competencia republicana. 


\section{Situando a questão a partir da formação inicial: a disciplina de Educação Brasileira no horizonte de um currículo comum de formação de professores}

"Democracia sem educação e educação sem liberdade são antinomias em teoria, que desfecham, na prática, em fracassos inevitáveis" (Anísio Teixeira).

O presente trabalho trata de aspectos da formação inicial no horizonte da Escola Republicana e Democrática (ERD) e tem como principal objetivo entender quais as noções que os professores da escola básica têm acerca da laicidade e, por consequência, intenciona-se dar visibilidade a esta perspectiva formativa como uma possibilidade de assegurar princípios republicanos e democráticos, evidenciados nas leis e diretrizes da sociedade brasileira. Entre elas destacamos a Lei de Diretrizes e Bases da Educação Nacional (LDB), Lei no 9.394/1996, e as Diretrizes Curriculares Nacionais da Educação Básica (DCNEBs/2016). Tais documentos evidenciam a gratuidade, a liberdade, a democracia, a alteridade, a diversidade, a inclusão e a laicidade como aspectos fundamentais, constitutivos da sociedade brasileira.

Os princípios supracitados são tematizados e refletidos a partir da noção de educação republicana e democrática em uma disciplina denominada de Educação Brasileira, que é comum a todos os cursos de formação de professores da Unijuí, RS. ${ }^{1}$ Nos currículos da referida instituição há um Núcleo Comum de Formação de Educadores (NCFP) que articula 11 disciplinas comuns, realizadas entre os cursos de Pedagogia, Educação Física, Matemática, Letras Português e Inglês, Ciências Biológicas e História. Esta organização curricular ocorreu pela visão de que determinados temas e conteúdos são relativos à docência, independentemente da área de atuação do professor, mas também por outras motivações, entre elas o fato de que os professores da educação básica constituem uma comunidade de saberes, que todos os professores respondem por um projeto pedagógico escolar e, ainda, as Diretrizes Curriculares Nacionais (DCNs) e a Base Nacional Comum Curricular (BNCC) orientam para uma perspectiva integradora ou interdisciplinar de construção curricular. Diante de tais aspectos, entende-se que é preciso integrar os diferentes cursos para que, posteriormente, na escola, os professores tenham uma visão geral e comum da educação e, por conseguinte, melhores condições de planejar e propor projetos inter-relacionados, uma vez que conhecem minimamente aspectos básicos das diretrizes da educação e das diferentes áreas de conhecimento. ${ }^{2}$ 
É neste contexto curricular que se situa a disciplina de Educação Brasileira (EB), e a partir dela é que se tratam os temas caros à formação de professores na expectativa de que os mesmos tenham noção do valor de determinadas conquistas sociais, resultado de lutas e movimentos em prol de direitos básicos e universais. A democracia e a laicidade são expressões dessas lutas, e constituem-se em dimensões políticas que asseguram a expressão da pluralidade humana. Preservá-las e atualizá-las começa pela sua ressignificação na formação inicial, concretizando-se no currículo laico da escola pública e realizando-se no mundo político, por meio da ação em prol de um mundo comum.

\section{Como nasce a pesquisa: diálogos entre acadêmicos e professores}

A disciplina de Educação Brasileira é ofertada no primeiro semestre dos cursos de formação de educadores da Universidade Regional do Noroeste do Estado do Rio Grande do Sul (Unijuí) e compõe a versão curricular 2014 dos cursos de formação de professores. Portanto, o período que abarca este estudo contempla os anos de 2014 a 2019, em ofertas de cursos presenciais e em modalidade a distância.

O programa da disciplina Educação Brasileira apresenta, entre outros referenciais teóricos, as obras de Teixeira (1978), Brayner (2008, 2015, 2016), Benevides (1996, 2016, 2019), Fensterseifer (2013) e Masschelein e Simons (2015), autores que sustentam a problematização do tema da escola republicana e democrática, tensionados a aspectos da Lei no 9.394/1996 e também das DCNEBs/2016. A partir destes referenciais busca-se dar uma noção geral do fundamento básico - republicano e democrático - da sociedade brasileira, que tem na laicidade a garantia da pluralidade e da democracia.

A tematização de tais pressupostos ganha maior relevância a partir de uma atividade conduzida na disciplina de EB, organizada a partir de uma consulta feita por meio dos acadêmicos aos professores de escolas públicas, em diferentes áreas de conhecimento. Os acadêmicos conversam com os professores acerca do entendimento de ERD e verificam, também, as possíveis implicações deste princípio em suas aulas, bem como no conjunto das atividades desenvolvidas nas escolas em que atuam. A partir deste diálogo, a questão adentra as aulas e é tematizada entre alunos e professor, não para negar o que fazem ou como fazem os professores, mas para se refletir o tema à luz da história da educação, do contexto atual e da especificidade da educação escolar. 
A mediação do professor fomenta a reflexão a partir de questões que suscitam a compreensão do viés republicano e democrático da educação brasileira e, que, por conseguinte, demandam uma postura pedagógica correspondente; significa afirmar que o professor atua a partir de uma normatização que torna a sua autonomia relativa. Neste horizonte, observa-se, inclusive, que certos temas ganham visibilidade de acordo com os dilemas específicos de um determinado contexto social. Nesse caso, exemplificamos a questão da liberdade de expressão, o lugar da opinião no processo de ensino e aprendizagem, questões que envolvem religião, gênero, políticas públicas de inclusão social, entre outros. Nesta disciplina tematiza-se, reflexivamente, portanto, sobre a educação brasileira e enfatiza-se a noção da ERD por entendermos que a compreensão deste fundamento político potencializa a percepção de que todos os que se ocupam da educação e da instrução pública o fazem no interior de um Estado laico, e isso diz respeito ao modo como as instituições e os sujeitos veem-se e agem a partir das tarefas que lhe competem no âmbito público.

Destaca-se, ainda, que a disciplina de Educação Brasileira está na sexta edição e é ofertada em dois campi. Diante de tal percurso, alavancou-se materiais importantes e depoimentos bastante contundentes dos professores, o que nos permite, inicialmente, três constatações: a primeira delas diz respeito ao desconhecimento do tema da ERD por uma parcela significativa de professores da nossa região, especialmente aqueles com mais de dez anos de atuação docente; a segunda é a (quase) ausência do tema em cursos de formação continuada; e a terceira constatação é a de que o tema da laicidade não é relacionado à ERD a partir dos estudos dos documentos oficiais, norteadores da educação básica, como a LDB, as DCNs e, mais recentemente, a BNCC.

A partir destas constatações básicas, pergunta-se sobre as razões desta invisibilidade conceitual, uma vez que a dimensão da laicidade é um aspecto constitutivo de sociedades republicanas e está na base da escola republicana. De outra parte, parece compreensível que os dilemas e os problemas enfrentados por muitos professores e alunos (tanto da escola básica quanto do Ensino Superior) acerca de temas sociais (já elencados), complexificam-se, muitas vezes, pela precária noção de laicidade na educação e, por conseguinte, pela ausência qualificada deste debate, especialmente nos cursos de FI e formação continuada. Destarte, argumenta-se a favor do estudo da ERD nos cursos de formação inicial, posto que a mesma é uma prerrogativa assegurada pela Constituição Brasileira de 1988. Compreender seu sentido histórico e social têm desdobramentos para a formação docente, uma vez que o professor da escola pública brasileira responde pela condução e reconvalida- 
ção de um projeto pedagógico nacional em uma sociedade republicana e democrática, ou seja, de viés laico.

Para sustentar este entendimento, o item que segue apresenta os fundamentos da ERD e, a partir disso, busca-se construir razões para sustentar a presença do tema na formação inicial dos licenciandos.

\section{Republicanismo e democracia: fundamentos da escola brasileira}

Por ERD entendemos aquela que se ocupa em conduzir um projeto de educação e instrução pública ${ }^{3}$ pautado na promoção da cidadania de todos e que se vale de uma tradição de conhecimentos e valores deliberados democraticamente; um projeto que tenha passado pelo crivo da sociedade, uma vez que essa orientação visa a um mundo comum. Esta noção de ERD toma como inspiração as ideias de Flávio Brayner (2016), para quem a educação republicana e democrática é aquela que corresponde à possibilidade de cada indivíduo tornar-se alguém. Por conseguinte, cabe à escola a condução deste processo formativo que deve, paulatinamente, conduzir o infante na construção de conhecimentos e valores que permitam, futuramente, adentrar no espaço público das deliberações e ações políticas.

Para tal propósito, Brayner (2016, p. 5) destaca algumas competências republicanas que constituiriam este horizonte de formação, “[...] que só fazem sentido em relação ao Outro", e tem na escola seu tempo/espaço ideal, mas não exclusivo: a competência argumentativa, propositiva, decisória e autointerrogativa. Para ele, a competência argumentativa tem a ver com a aquisição de códigos linguísticos, o direito à palavra como linguagem de autoridade e um certo poder de impor a recepção, contudo "[...] precisa ser o resultado da possibilidade, sempre aberta e renovada, do encontro entre alteridades" (BRAYNER, 2016, p. 6). O autor menciona que esta competência se articula com outras duas, que são a competência proposicional e a competência decisória e, neste sentido, argumenta que a capacidade de propor é coetânea à capacidade de argumentar, uma vez que:

[...] toda argumentação é também proposição: sugere-se a um Outro um ponto de vista, um acordo a partir de bases negociadas, os termos em que se dará o próprio fundo comum da discussão, etc. Propor significa, acima de tudo, reconhecer que todo argumento individual - um ponto de vista - é necessariamente frágil, e que só na situação em que ele recebe adesões e vem a se constituir num fundo comum de interesses - um "mundo" -, é que ele conhece sua fortaleza (BRAYNER, 2016, p. 7-8). 
O argumento e a proposição fazem-se encaldados por uma motivação da ordem da ação e, geralmente, requerem do sujeito também a capacidade de decidir e se autointerrogar. Brayner (2016) define a competência decisória como sendo "[...] aquela que nos permite escolher entre alternativas, desde que estas tenham sido validadas na sua substância e nas suas consequências sociais ou individuais" (p. 8) e, assim, a competência autointerrogativa colocaria o sujeito diante da possibilidade de um pensamento autoavaliativo, levando-o a mobilizar valores, princípios e fundamentos. Para Brayner (2016), a competência autointerrogativa é:

[...] sinônima da capacidade de autoinstituição do social (Castoriadis): uma sociedade que sabe que criou suas próprias instituições e a elas se submete com consciência, ou as abandona no momento em que elas não mais convêm, através do exercício da crítica e da re-significação (BRAYNER, 2016, p. 9).

É importante destacar o entendimento de Brayner (2016) acerca da efetividade da aquisição de tais competências, pois, para ele, a aquisição das mesmas não garante a instalação e/ou preservação da democracia social e política. Infere-se, então, que educar no horizonte da ERD é, antes de mais nada, uma aposta no indivíduo e na sua capacidade deliberativa em perspectiva de um mundo comum, ou seja, aquele que diz respeito a todos. Nas palavras de Arendt (2001, p. 65),

O mundo comum é aquilo que adentramos ao nascer e que deixamos para trás quando morremos. Transcende a duração de nossa vida, tanto no passado quanto no futuro: preexistia à nossa chegada e sobreviverá à nossa breve permanência. É isto o que temos em comum, não só com aqueles que vivem conosco, mas também com aqueles que aqui estiveram antes e aqueles que virão depois de nós.

Em perspectiva semelhante, recorre-se às ideias de Benevides (2019), que menciona ser a educação para a democracia uma aposta na conquista de um mundo comum. Para esta autora, tal perspectiva permite a formação do cidadão para viver os grandes valores democráticos que englobam as liberdades civis, os direitos sociais e os de solidariedade dita "planetária". Para Benevides (1996, p. 226), a educação para a democracia comporta duas dimensões:

[...] a formação para os valores republicanos e democráticos e a formação para a tomada de decisões políticas em todos os níveis, pois numa sociedade verdadeiramente democrática ninguém nasce governante ou governado, mas pode vir a ser, alternativamente - e mais de uma vez no curso da vida - um ou outro.

Tanto Benevides (2016) quanto Brayner (2016) apostam em uma educação para saber discutir e escolher. 
Nesse panorama, qual seria a tarefa ou função da escola? O que pode ela propor a favor de uma formação para a democracia? Para Brayner (2016, p. 5), a escola "[...] é este lugar social precisamente designado e pensado para estabelecer relações (entre o passado e o futuro, entre as gerações, entre os mortos e os vivos) e fornecer aos sujeitos que a frequentam, mínimas condições de se tornarem 'visíveis"'.

Segundo Fensterseifer (2013), a escola tem uma função pública, uma vez que ela responde por uma expectativa social, de caráter político, considerando que o caráter de "artificialidade" do mundo humano somente se mantém pela intencionalidade a que instituições como a escola se propõe. A escola nasce das necessidades da sociedade moderna em suprir demandas do universo político e do mundo do trabalho, mais particularmente do âmbito científico e filosófico, que, a rigor, as famílias não dariam conta de transmitir de modo qualificado. $\mathrm{O}$ autor evidencia que a escola tem um triplo sentido: a) produção e renovação da cultura; b) estabelecimento e reforço das solidariedades; c) formação de identidades. Destaca Fensterseifer (2013, p. 131) que "a escola não deve ser confundida com roda de amigos (embora possibilita a convivência e a socialização), púlpito de igreja, palanque eleitoral, sindicato, sociedade beneficente ou instituição de caridade e extensão da família”.

Diante de tais aspectos, é plausível afirmar que à escola compete algo diferenciado, relativo à sua especificidade. Esta constatação, um tanto óbvia, necessita ser colocada no centro dos debates quando a questão é a formação de professores e educação pública, pois a questão acerca da especificidade da educação escolar nos faz repensar certas posturas quase naturalizadas no ensino, entre elas a ênfase na opinião, no gosto pessoal, na crença individual e, por vezes, na deliberada autonomia do professor diante aos documentos oficiais (Constituição, LDB, DCN). ${ }^{4}$

Fensterseifer (2013) assevera que a educação pressupõe normatividade, devendo reconhecer o caráter propositivo deste telos para formação do sujeito, o que não a isenta da constante justificação; ao contrário, a exige, diferenciando-se, assim, de perspectivas educacionais autoritárias fundadas em uma racionalidade instrumental. Neste sentido, a escola pública é normatizada pelas leis da república, pelas diretrizes, pelas deliberações das instituições oficiais de educação, bem como pelos acordos que nascem do debate público que envolve as comunidades científicas, os professores e o público em geral. Outras questões, contudo, também se colocam para esta instituição, que diz respeito àquilo que a humanidade já produziu e que deixa como herança aos recém-chegados ao mundo humano. Neste sentido, destacamos os valores universais que são revalidados no interior de cada 
instituição escolar, e igualmente por meio de cada professor, ao modo como os assume e os transmite.

Se isso tem razoabilidade, então, cabe-nos considerar os acordos coletivos (objetificados em leis) como ponto de partida e levá-los em conta no momento em que elaboramos os projetos escolares, os planos de ensino e/ou de trabalho e, mais especificamente, em relação aos aspectos relativos à condução das aulas. Por conseguinte, assume-se o entendimento de que a escola cumpre uma função que é acordada socialmente, e, por isso, estaria ela subsumida aos acordos e às leis da República.

Diante de tais ponderações reitera-se as competências mencionadas por Brayner (2016), relacionando-as a este desafio de cada cidadão em assumir as pautas que se apresentam a cada contexto e se colocar na perspectiva de contribuir na construção, validação e reconvalidação de uma sociedade mais justa, plural e democrática. Pois: "Uma reflexão sobre os fins da educação é uma reflexão sobre o destino do homem, sobre o lugar que ele ocupa na natureza, sobre as relações entre os seres humanos" (DELVAL apud SAVATER, 2000, p. 55).

\section{A laicidade: um desafio a ser enfrentado com responsabilidade e espírito}

\section{republicano}

Iniciamos a questão destacando um aspecto fundamental: o laicismo é incompatível com o fanatismo/sectarismo; é o espaço da pluralidade, do debate, da expressão das vozes. Para Maamari (2014, p. 89), a laicidade é explicada como sendo “[...] o regime em que nenhum indivíduo possa ser discriminado em razão das suas orientações de vida, pois estaria assegurada a liberdade de consciência diante de um Estado que pertença a todos (povo) e não somente a uma parte da população".

Este princípio é um desafio histórico das sociedades modernas e ganha visibilidade a partir das Revoluções Americana (1776) e Francesa (1789), na medida em que foi articulado às conquistas sociais, as quais mobilizaram as pessoas a erguerem bandeiras em prol da igualdade entre os cidadãos e das liberdades individuais.

Entre estas liberdades individuais situa-se a liberdade de crença, pressupondo um ensino laico que não se opõe a existência de diversas religiões, ao contrário, as preserva ao não as hierarquizar. Em caso de eleger uma em detrimento das outras, estas preteridas correriam o risco de extinção, negando assim a pluralidade de opções. Segundo Maamari (2009, p. 69): “O poder público não pode julgar a verdade 
de uma religião, portanto institucionalizá-la seria uma tirania sobre as opiniões, constituindo um ato totalmente contrário à política e à moral" ${ }^{5}$

Laicidade é então a garantia da pluralidade, das liberdades sociais e individuais, pautadas, sim, pelo espírito das repúblicas democráticas. Isso significa, que a laicidade acolhe a diferença e acena para a alteridade, pois permite ver o outro como Outro. Neste sentido, Coutel, em sua obra Condorcet, instituir el ciudadano (2004), considera que sem o princípio do laicismo, fica inviabilizada a instituição cívica da cidadania, dado ser ele o móvel de uma racionalidade política que aspira a universalidade (COUTEL, 2004).

Diante de tais argumentos, evidencia-se que a laicidade, como um dos princípios da escola republicana, estaria equivocada se associada ao estabelecimento do ensino da moral à religião, pois a moral ultrapassa dimensões religiosas para se vincular a um debate ético pautado por princípios universais. Nessa perspectiva, Brutti (2014, p. 407) evidencia que

O espírito público (laicismo) não equivale a uma opinião entre tantas outras. Ele constitui a própria garantia de que todas as opiniões possam ser manifestadas e discutidas na esfera pública, exceto se buscarem (re)estabelecer despotismos ou cultivar fanatismo políticos e religiosos.

Cabe reforçar que em sociedades democráticas e republicanas o telos da educação não deve se sobrepor ao telos que a própria sociedade, no exercício da cidadania, se dá.

\section{A escola no horizonte da educação republicana e democrática: a questão da instrução e da formação para a cidadania}

Os ensinamentos possibilitados no âmbito da escola são fundamentais para a manutenção das tradições do mundo humano, mas, também, para a sua desconstrução e posterior ressignificação. Para este processo, conta-se, especialmente, com um professor sabedor das leis e dos princípios básicos da sociedade. Sendo assim, os temas que a escola aborda são tanto aqueles legitimados pela comunidade científica quanto os emergentes em contextos sociais específicos. Muitos deles novos para todos nós ou, pelo menos, possuidores de uma nova roupagem. Por isso, exigem de cada professor o desafio de atualização e compreensão de seus sentidos sociais, para que a mediação de tais abordagens possa se dar de modo qualificado e laico. 
Benevides (2019) considera ótimo que estes princípios sejam contemplados pela legislação, mas, em não estando, deveriam, mesmo assim, ser reconhecidos. A autora interroga-se e responde:

Por que são universais e devem ser reconhecidos, se não existe nenhuma legislação superior que assim o obrigue? Essa é a grande questão da Idade Moderna. Porque é uma grande conquista da humanidade ter chegado a algumas conclusões a respeito da dignidade e da universalidade da pessoa humana, e do conjunto de direitos associados à pessoa humana. É uma conquista universal que se exemplifica no fato de que hoje, pelo menos nos países filiados à tradição ocidental, não se aceita mais a prática da escravidão. A escravidão não apenas é proibida na legislação como ela repugna a consciência moral da humanidade. Não se aceita mais o trabalho infantil. Não se aceitam mais castigos cruéis e degradantes (BENEVIDES, 2019, p. 5).

É neste sentido que este texto trata da questão da ERD com ênfase para a formação inicial dos professores, uma vez que o estudo produzido no interior da disciplina de Educação Brasileira evidencia que há uma preponderância de visões subjetivas por parte do professor quando certos temas aparecem nas aulas, como religião, política (partidária), questões de gênero e sexualidade, aborto, família e formação de valores.

O estudo indica, inclusive, que são significativos a prática de orações (predomínio do viés cristão) nas aulas, os cultos em eventos festivos, as canções com mensagens moralistas, entre outros aspectos, o que nos leva a relacionar tais posturas com a ausência do debate acerca do caráter laico da escola pública.

Conforme Brutti (2014, p. 117), a educação republicana "não anula as diferenças individuais e a diversidade de talentos e profissões, senão que previne do risco que essas diferenças se traduzam em hierarquia social não acordada entre os cidadãos".

Maamari (2009) defende que a moral a ser desenvolvida pela instrução é uma moral racional que resulte, de fato, na autonomia do indivíduo; o ensino da moral visa a uma consciência independente, isto é, fazer uso do seu entendimento sem a tutoria de outrem. Argumenta a autora:

A escola institui a República e por isso deve ser por ela mantida de modo a protegê-la contra as tentações demagógicas e sofísticas e em defesa da verdade e da liberdade que lhe deram origem. Para que isto se torne possível é necessário que se mantenha a escola com autonomia. Ela deve estar livre dos imperativos econômicos conjunturais; deve impedir que qualquer tipo de dogma esteja presente nas aulas; por fim, deve afastar a ameaça de que interesses particulares de alguns substituam o desenvolvimento das crenças de modo livre e autônomo pelos cidadãos (MAAMARI, 2009, p. 80). 
Desse ponto de vista, evidencia-se a aposta na educação do sujeito ao assumir-se que a escola, como instituição laica, apresenta os temas e possibilita seu debate, numa convicção de que o sujeito pode construir seus pontos de vista na medida em que acessa informações plurais, mediadas por um professor capacitado a um debate em que as divergências aflorem e sejam tensionadas às perspectivas universalizantes. Também podemos observar, em Benevides (2016, p. 29-30), a aposta na educação autônoma dos sujeitos:

A política e o exercício do poder são necessários e indispensáveis. Mas trazem, em si, a possibilidade do abuso, da manipulação, e as consequências costumam ser catastróficas. Tenho enorme admiração por todos aqueles que se envolvem diretamente com tarefas políticas e o exercício do poder, tendo como principal compromisso a prática dos valores republicanos e democráticos - ou seja, a prioridade ao bem comum, acima dos interesses particulares e privados, o respeito à igualdade de todos em dignidade, a garantia a todos de acesso aos bens e serviços sociais, à cidadania ativa, enfim.

Benevides (2019, p. 3) deixa uma provocação para pensarmos o assunto na medida em que reafirma a escola como este locus privilegiado de formação:

Onde deve ser desenvolvida a educação do cidadão? A escola é o locus privilegiado, embora sofra, atualmente, a concorrência de outras instituições - como os meios de comunicação de massa. A escola continua sendo a única instituição cuja função oficial e exclusiva é a educação. É evidente que existem outros espaços para a educação do cidadão, dos partidos aos sindicatos, às associações profissionais, aos movimentos sociais, aos institutos legais de democracia direta. Mas a escola não deve substituir a militância, pois forma cidadãos ativos e livres, e não, como alertava Fernando de Azevedo, homens de partido, de facções virtualmente intolerantes.

Nesta direção, tomamos a ideia de Masschelein e Simons (2015), que fazem uma defesa da escola em seu aspecto de escolé, ou seja, recuperam a noção grega de escola com um tempo livre, um lugar privilegiado no qual as crianças e os jovens estariam livres da família, da religião, do trabalho e da política. Para estes autores, "a escola cria igualdade precisamente na medida em que constrói o tempo livre, isto é, na medida em que consegue, temporariamente, suspender ou adiar o passado e o futuro, criando, assim, uma brecha no tempo linear" (MASSCHELEIN; SIMONS, 2015, p. 36).

Nossa expectativa é de que a escola possa constituir-se em um tempo/espaço de vivências em direção à alteridade. Que a mesma possibilite ao sujeito pensar as questões de seu tempo, mediadas por professores sensíveis, que permitam radicalizar o princípio expresso nas DCNs de conduzir os alunos a uma formação ética, estética e inclusiva, radicalizando o todos com o propósito da perfectibilidade, que deve caracterizar uma sociedade republicana e democrática, uma vez que: "O 
homem é um ser livre para deliberar, votar e escolher a lei que decide obedecer. A cidadania resultaria na escolha livre e esclarecida pela instrução" (MAAMARI, 2009, p. 74). Por fim, reafirmamos a provocação deixada por Brayner (2016, p. 6):

A fragilidade de minha posição talvez resida no fato de esperar que a educação escolar possa proporcionar a cada um esta competência cidadã que, na verdade, não é um privilégio mas uma necessidade do debate público ampliado. Mas se a escola não puder fazê-lo, como continuar a falar de uma educação para a cidadania?

Mesmo sabendo que o exercício cidadão não prescinde da educação escolar, é impossível ignorar que a instrução, sustentada em conhecimentos de natureza científica, filosófica, artística, somada aos aspectos educacionais da convivência ética, pautada por valores democráticos e republicanos, tenha se tornado fundamental para uma cidadania plena em sociedades complexas como as em que vivemos.

\section{Para seguir pensando na escola republicana...}

Reconhecer a escola como uma instituição "artificial", que se ocupa da educação, da instrução e da formação, passou a ocupar um lugar de destaque na manutenção dos valores democráticos e republicanos, porém somos convocados a nos manifestar acerca da sua fragilização no tempo presente, que compromete também os frágeis preceitos das sociedades fundadas nestes valores.

O esforço educativo da escola republicana e democrática realiza-se, inclusive, ao evidenciar seus limites e fragilidades, tal como é o próprio humano, e nisso cumpre papel importante, pois nos previne das tentações autoritárias que prometem resolver "de vez" nossos problemas, ignorando que na processualidade do "a cada vez" é que se manifesta a razoabilidade da condição humana nas sociedades autônomas.

A escola, assim desejamos, deve manter-se como um lugar plural, acolhedor das diferenças e, por isso mesmo, fundamental para a convivência entre os sujeitos. Entendemos que ela realiza este papel quando tematiza a constituição destas diferenças, não as absolutizando, mas tencionando-as de um ponto de vista capaz de viabilizar um mundo comum, em que as diferenças revelem a pluralidade, sem hierarquizá-las.

Na medida em que possibilita ser-com-o-outro, a escola já cumpre um papel fundamental, uma vez que cria situações em que é preciso seguir normas de convivência, exigindo a construção de acordos, permitindo a isonomia e potencializando 
a autonomia, argumentos que consideramos relevantes para nos opormos às saídas individualizadas, como a educação domiciliar (homeschooling), ou aquelas pautadas exclusivamente pela virtualidade das relações.

A formação inicial e continuada requer a consideração das leis, normas e diretrizes, pois tais normatizações não devem ser vistas como "opressivas”, afinal, em sociedades democráticas, elas expressam a objetivação do consenso possível entre os atores políticos. Por outro lado, o reconhecimento desta legitimidade não deveria significar uma posição acrítica diante delas, mas de constante avaliação, com vistas ao seu aperfeiçoamento, necessitando ressignificações à luz dos desafios contemporâneos.

A universidade precisa ocupar-se de tais estudos e tematizações, contribuir para a leitura crítica dos marcos legais e, ao mesmo tempo em que reconhece a normatividade instituída, deve lembrar o caráter instituinte do exercício cidadão, o qual tem na formação inicial um momento privilegiado com a constituição da docência, em particular da escola pública, mas de maneira mais ampla, com os preceitos republicanos de toda educação.

Mesmo sem garantias de desdobramentos positivos ao intento aqui exposto, reitera-se a importância deste debate na formação inicial docente por acreditar-se na sua pertinência, mas, também, pela urgência do tema em uma sociedade que tem balizado seus valores quase que exclusivamente pela religião e pela "família", duas instituições que, por mais importantes que sejam, não são instituições democráticas. Enfim, releva saber que as liberdades que gozamos são tão frágeis quanto as instituições que as garantem; assim, cabe sempre lembrar às novas gerações, em particular àquelas que se ocuparão da educação, que a responsabilidade sobre elas é uma tarefa de todos; aprendizagem não vem no "pacote genético", portanto precisa ser desenvolvida.

\section{Notas}

1 Disciplina que compõe o currículo comum dos cursos de formação de professores da Unijuí, uma instituição comunitária que tem uma tradição de mais de 70 anos voltada à formação superior de professores, com abrangência nacional.

2 Destacamos dois componentes curriculares deste currículo comum: Prática de Ensino Interárea: Ensino Fundamental e Prática de Ensino Interárea: Ensino Médio. Tais disciplinas proporcionam aulas pelo viés da interdisciplinaridade, nas quais os alunos constituem grupos de diferentes áreas de conhecimento e desenvolvem projetos para o Ensino Fundamental e Médio, integrando conteúdos e conhecimentos a partir da metodologia de Situação de Estudos (Gipec/Unijuí).

3 A noção de instrução pública é herdeira dos debates travados por ocasião da instituição da ER na França pós-revolucionária, em particular nos textos de Condorcet (2008). 
4 Excessos de subjetivismo que parecem ignorar que em uma República as instituições, e aqueles que nelas atuam, devam se pautar pelas leis, tendo, portanto, uma autonomia reativa.

5 O que também vale para as posições políticas, ideológicas, compatíveis com a pluralidade democrática, originando a ideia de poder como "lugar vazio" (não é encarnado por nenhuma posição), e a distinção entre Estado e governos.

\section{Referências}

ARENDT, H. A condição humana. Tradução Roberto Raposo. Revisão e apresentação Adriano Correia. 11. ed. rev. Rio de Janeiro: Forense Universitária, 2001.

BENEVIDES. M. V. M. A educação para a democracia. Revista Lua Nova, São Paulo, n. 38, p. 223-237, dez. 1996. Disponível em: https://www.scielo.br/scielo.php?pid=s0102-644519960002 00011\&script=sci_arttext. Acesso em: 9 ago. 2019.

BENEVIDES. M. V. M. Cidadania ativa e democracia no Brasil. Revista Parlamento e Sociedade, São Paulo, v. 4, n. 6, p. 21-31, jan./jun. 2016. Disponível em: https://www.al.sp.gov.br/alesp/ biblioteca-digital/obra/?id=22728. Acesso em: 9 ago. 2019.

BENEVIDES. M. V. M. Educação para a cidadania na democracia contemporânea. São Paulo: Instituto de Estudos Avançados da Universidade de São Paulo, 2019. Disponível em: http:// www.iea.usp.br/publicacoes/textos/benevidescidadaniaedireitoshumanos.pdf. Acesso em: 9 ago. 2019 .

BRASIL. [Constituição (1988)]. Constituição da República Federativa do Brasil de 1988. Brasília, DF: Presidência da República [2016]. Disponível em http://www.planalto.gov.br/ccivil_03/ constituicao/constituicaocompilado.htm. Acesso em: 6 jun. 2019.

BRASIL. Ministério da Educação e Cultura. Lei de Diretrizes e Bases da Educação Nacional - LDB n. 9.496/1996. Disponível em: https://www2.senado.leg.br/bdsf/bitstream/handle/ id/529732/lei_de_diretrizes_e_bases_1ed.pdf. Acesso em: 6 jun. 2019.

BRASIL. Ministério da Educação e Cultura. Diretrizes Curriculares Nacionais da Educação Básica - DCNEB/2016. Disponível em: http://portal.mec.gov.br/index.php?option=com_docman\&view=download\&alias=13448-diretrizes-curiculares-nacionais-2013-pdf\&Itemid=30192. Acesso em: 6 jun. 2019.

BRAYNER, F. H. Educação e republicanismo. Notas arendtianas para uma educação melhor. Brasília, DF: LiberLivro, 2008.

BRAYNER, F. H. Fundamentos da educação. Crise e reconstrução. Campinas, SP: Mercado das Letras, 2015.

BRAYNER, F. H. Educação popular e "competência” republicana - Ufpe GT: Educação Popular, n. 6. In: ANPED, 29, 2016, Caxambu, MG, 2016. Disponível em: https://anped.org.br/sites/default/files/gt06-2189.pdf. Acesso em: 9 ago. 2019.

BRUTTI, T. A. Laicidade. In: GONZÁLEZ, F. J.; FENSTERSEIFER, P. E. (org.). Dicionário crítico de Educação Física. 3. ed. Rev. e ampl. Ijuí: Editora Unijuí, 2014. p. 403-408.

COUTEL, Charles. Condorcet, instituir el ciudadano. Buenos Aires: Ediciones del Signo, 2004. 
CONDORCET, M.-J. A. N. de C., M. de. Cinco memórias sobre a instrução pública. São Paulo: Ed. Unesp, 2008.

FENSTERSEIFER, P. E. Função da escola pública. In: SANTIAGO, A. R.; FEIL, I. T. S.; ALLEBRANT, L. I. (org.). O curso de Pedagogia na Unijuí - 55 anos. Ijuí: Editora Unijuí, 2013. p. 123-147.

MAAMARI, A. M. A fundamentação filosófica da escola republicana. Contexto \& Educação, Ijuí: Editora Unijuí, ano 24, n. 82, jul./dez. 2009. Disponível em: https://www.revistas.unijui.edu.br/ index.php/contextoeducacao/article/view/1012. Acesso em: 5 mar. 2015.

MAAMARI, A. M. O ensino laico e a formação filosófica. Revista Eletrônica de Educação, v. 8, n. 3, p. 86-95, 2014. Disponível em: http://www.reveduc.ufscar.br/index.php/reveduc/article/ view/1090. Acesso em: 5 mar. 2015.

MASSCHELEIN, J.; SIMONS, M. Em defesa da escola. Tradução Cristina Antunes. 2. ed. 1. reimpr. Belo Horizonte: Autêntica, 2015.

SAVATER, F. O valor de educar. São Paulo: Martins Fontes, 2000.

TEIXEIRA, A. S. Pequena introdução à filosofia da educação: a escola progressiva ou a transformação da escola. 8. ed. São Paulo: Editora Nacional, 1978. 